\title{
Associations between stressors and difficulty sleeping in critically ill patients admitted to the intensive care unit: a cohort study
}

Roberto Carlos Miranda-Ackerman, Mariana Lira-Trujillo', Alma Carolina Gollaz-Cervantez', Ana Olivia Cortés-Flores', Carlos José Zuloaga-Fernández del Valle', Luis Alberto García-González', Gilberto Morgan-Villela', Francisco José Barbosa-Camacho², Kevin Josue Pintor-Belmontes², Bertha Georgina Guzmán-Ramírez² , Aldo Bernal-Hernández² ${ }^{2}$ Clotilde Fuentes-Orozco ${ }^{2}$ and Alejandro González-Ojeda ${ }^{2^{*}}$ (D)

\begin{abstract}
Background: Patients admitted to the intensive care unit (ICU) experience sleep disruption caused by a variety of conditions, such as staff activities, alarms on monitors, and overall noise. In this study, we explored the relationship between noise and other factors associated with poor sleep quality in patients.

Methods: This was a prospective cohort study. We used the Richards-Campbell Sleep Questionnaire to explore sleep quality in a sample of patients admitted to the ICU of a private hospital. We measured the noise levels within each ICU three times a day. After each night during their ICU stay, patients were asked to complete a survey about sleep disturbances. These disturbances were classified as biological (such as anxiety or pain) and environmental factors (such as lighting and ICU noise).

Results: We interviewed 71 patients; $62 \%$ were men (mean age 54.46 years) and the mean length of stay was 8 days. Biological factors affected $36 \%$ and environmental factors affected $20 \%$ of the patients. The most common biological factor was anxiety symptoms, which affected $28 \%$ of the patients, and the most common environmental factor was noise, which affected 32.4\%. The overall mean recorded noise level was $62.45 \mathrm{~dB}$. Based on the patients' responses, the environmental factors had a larger effect on patients' sleep quality than biological factors. Patients who stayed more than 5 days reported less sleep disturbance. Patients younger than 55 years were more affected by environmental and biological factors than were those older than 55 years.

(Continued on next page)
\end{abstract}

\footnotetext{
* Correspondence: avygail5@gmail.com

Unidad de Investigación Biomédica 02, Hospital de Especialidades del Centro Médico Nacional de Occidente, Instituto Mexicano del Seguro Social, Avenida Belisario Domínguez \# 1000 Col. Independencia, 44340 Guadalajara, Jalisco, Mexico

Full list of author information is available at the end of the article
}

(c) The Author(s). 2020 Open Access This article is licensed under a Creative Commons Attribution 4.0 International License, which permits use, sharing, adaptation, distribution and reproduction in any medium or format, as long as you give appropriate credit to the original author(s) and the source, provide a link to the Creative Commons licence, and indicate if changes were made. The images or other third party material in this article are included in the article's Creative Commons licence, unless indicated otherwise in a credit line to the material. If material is not included in the article's Creative Commons licence and your intended use is not permitted by statutory regulation or exceeds the permitted use, you will need to obtain permission directly from the copyright holder. To view a copy of this licence, visit http://creativecommons.org/licenses/by/4.0/ The Creative Commons Public Domain Dedication waiver (http://creativecommons.org/publicdomain/zero/1.0/) applies to the data made available in this article, unless otherwise stated in a credit line to the data. 
(Continued from previous page)

Conclusions: Patient quality of sleep in the ICU is associated with environmental factors such as noise and artificial lighting, as well as biological factors related to anxiety and pain. The noise level in the ICU is twice that recommended by international guides. Given the stronger influence of environmental factors, the use of earplugs or sleeping masks is recommended. The longer the hospital stay, the less these factors seem to affect patients' sleep quality.

Keywords: Critically ill patient, ICU, Sleep, Stressors

\section{Background}

Sleep is a basic human need and is closely related to health and disease recovery. From the moment they enter an intensive care unit (ICU), patients in a critical state must deal with a variety of challenges that require adaptation to the ICU environment $[1,2]$. This experience can be unfamiliar and disorienting, and patients' interactions and sensations can be limited. For example, ICU patients are subjected to continuous stimuli that can alter their sleep schedule [3, 4]. The main sources of disturbance of ICU patients' sleep include nurse and physician activities, family visits, and alarms [5-7]. Patients in the ICU may remain in a chronic state of alertness because of the continuous sounds of alarms. Ryherd et al. exposed volunteers to an environment that simulated the ICU and found sleep alterations and elevated levels of biochemical markers of stress [8].

Poor sleep quality adversely affects vegetative functions and peripheral vascular tone, both of which are closely related to the recovery process in critical patients [9]. Poor sleep quality can alter the immune response, which may increase the patient's susceptibility to infection. Studies report that sleep disturbance can also cause disequilibrium between the sympathetic and parasympathetic nervous systems, which can change arterial blood pressure, cause tachycardia, increase oxygen consumption, induce hypoxemia, and decrease erythropoiesis [10, 11]. This is particularly important for ICU patients because their clinical evolution depends on both the etiology and treatment options available. ICU patients' recovery can be impaired by preexisting sleeping disorders, which when added to those caused by the ICU environment, may worsen their experience in the ICU [12].

Studies have reported a relationship between the ICU environment and the perception of interrupted sleep or difficulties falling asleep. Noise is generated by a variety of sources within the ICU, such as conversations between nursing and medical staff, opening and closing of doors, family visits, ringing telephones, and noise from radios, televisions, and patient monitoring systems [5, $13,14]$. In addition, the placement of equipment can limit the inability to move freely, which can contribute to patient discomfort $[2,15]$. The World Health
Organization (WHO) suggests that noise levels inside a hospital should be $35 \mathrm{~dB}(\mathrm{~dB})$ during the day and $30 \mathrm{~dB}$ at nighttime, although these requirements are not always met [16]. ICU staff need to be aware of how environmental and biological factors can affect ICU patients' sleeping patterns and their ability to rest.

\section{Methods \\ Aims}

The aims of this study were to identify factors associated with difficulty sleeping in critically ill patients in the ICU of a private hospital and to compare the effects of biological and environmental factors, such as noise level within the ICU, on patients' sleep. The study's hypothesis was that environmental and biological factors have detrimental effects on patients' sleep quality in the ICU.

\section{Design}

This was a prospective cohort study that evaluated the influence of biological and environmental factors in critically ill patients admitted to the ICU in a private hospital. The ICU is divided into a general ICU ( 8 beds) and a step-down unit ( 8 beds), representing a total of 16 beds. The step-down unit provides an intermediate level of care for patients with higher requirements than can be delivered in the general ward. The participant inclusion period was from January 2019 to May 2019.

The research team conducted interviews of all patients admitted to the ICU. These interviews took place during the morning shift each day for the length of the participants' ICU stay. The procedures used for data collection are described in the following paragraphs.

To measure sleep quality, we used the validated Spanish language version of the Richards-Campbell Sleep Questionnaire (RCSQ) [17]. For this questionnaire, the patient is given a $100 \mathrm{~mm}$ visual analogue scale and places a mark on the line that best represents the quality and quantity of sleep. The line has two options at each extreme: one to record the best quality ("deep sleep") and on other the worst quality ("light sleep"). To obtain a final score, the patient's answers are measured with a ruler. A total score of 0-33 represents poor quality sleep, 34-66 represents average quality sleep, and 67100 represents good quality sleep. 
Afterwards, we asked the patients to give a reason why their sleep was disturbed. We categorized the stressors into factors as referred to in the North American Nursing Diagnosis Association (NANDA) [18], i.e., environmental factors and biological factors. Environmental factors included noise, temperature, and lighting in the ICU. Biological factors included pain, dyspnea, delirium, vomiting, encephalopathy, bronchospasm, diarrhea, and anxiety. Anxiety was defined as an anxious adjustment disorder in patients who mentioned feeling anxious to the ICU physicians, nurses, or medical staff. The following symptoms were assumed to relate to signs of patient anxiety: feeling nervous, irritable, and/or afraid because of their condition or treatment/procedures, fear of losing control, and somatic symptoms such as tachycardia, sweating, restlessness, and trembling) [19]. These stressors were measured using a survey that included questions about the causes of the patients' sleep disturbance.

Additionally, we measured the noise levels within each of the ICUs. The sound data were collected using a microphone with a sensitivity range of $0-100 \mathrm{~dB}$. Sound was measured three times a day in the morning, afternoon, and night on each day. The sound was recorded in occupied rooms for $60 \mathrm{~min}$ from the middle of the unit to obtain a general idea of the sound panorama inside of the unit for each shift. We included these data in the database for the corresponding shift (morning, afternoon, or night shift). Finally, we averaged the sound levels obtained for each patient to obtain the mean sound levels for each unit. The sound levels were recorded by an ICU physician, nurse, or medical student.

\section{Sample and participants Sample size}

The sample size was calculated according to the prevalence of sleep difficulties in patients hospitalized in general wards (50\%) compared with those patients admitted to the ICU (80\%) [20]. We used a difference between proportion formula, a two-sided confidence level of $95 \%$, and a power of $80 \%$ to calculate a minimum sample size of 66 patients. The total number of patients admitted to the ICU during the recruitment time was 157. Our final sample included 71 patients who met the following inclusion criteria.

\section{Inclusion criteria}

1. Age $>18$ years

2. Patients admitted in the ICU or step-down unit for $>24 \mathrm{~h}$

3. Patients who were not prescribed any adjuvant sleeping medication (such as benzodiazepines, dexmedetomidine, or haloperidol)
4. Patients with no preexisting sleep disorders (such as insomnia, obstructive sleep apnea, circadian rhythm sleep syndrome, or narcolepsy).

During the admission, patients were asked whether they took any medication (including adjuvant sleep medication) or if they had any chronic condition (the admission form includes an item for mental disorders).

\section{Exclusion criteria}

1. Patients prescribed an adjuvant sleeping medication during their ICU stay

2. Patients prescribed adjuvant sleeping medications before admission to the ICU

3. Patients with a preexisting sleeping disorder

4. Patients with a preexisting anxiety disorder.

The patients were divided into age groups, and the ICU length of stay was divided into groups using the median split. For the age groups, 36 patients (50.7\%) were included in the $\leq 55$-year-old group and 35 patients (49.3\%) in the $>55$-year-old group. For ICU stay length, 38 patients $(53.5 \%)$ were included in the $\leq 5$ days group and 33 patients $(46.5 \%)$ were included in the $>5$ days group.

\section{Data analysis}

Data were analyzed using Statistical Package for Social Sciences (version 23 for Windows; IBM SPSS, Armonk, NY, USA). Descriptive statistics included percentage, mean, and standard deviation. Inferential analysis was performed using the chi-square test or Fisher's exact test. Levene's test was used to test for equality of variances for quantitative variables and showed that the data had a normal distribution. Student's $t$ test and analysis of variance (ANOVA) were used to analyze continuous variables. A two-sided $p<0.05$ was considered to be significant.

\section{Results}

We interviewed 71 patients during their hospital stay: 44 (62\%) men and 27 (38\%) women. Their mean age was $54.46 \pm 18.4$ years (range 16-92 years).

We examined whether the patients had a full night of sleep according to the length of hospital stay. In the group of patients who stayed $\leq 5$ days in the ICU, 38 $(81.5 \%)$ reported disturbed sleep, and seven patients (18.4\%) had a full night of sleep during their stay. Of the 33 patients who stayed $>5$ days in the ICU, only one reported having a full night of sleep, and 32 patients (96.9\%) reported disturbed sleep. However, the differences between groups did not reach statistical significance $(p=0.060)$. 
In the $\leq 55$-year-old group, two patients reported they had slept all night without disturbances, and 34 patients (94.4\%) reported disturbed sleep. In the $>55$-year-old group, six patients (17.1\%) reported a full night of sleep, and 29 patients $(82.8 \%)$ reported disturbed sleep. The differences were not significant $(p=0.151)$.

\section{Stressors}

The most common environmental factor was noise, which was reported by 23 patients (32.4\%), followed by ICU lighting (14 patients, 19.70\%). When asked about which source of the sound patients found more disturbing, the primary sources were staff activities, telephones ringing, monitors and infusion pump alarms, and chairs moving. The most common biological factor was anxiety, which was reported by 20 patients (28.20\%), followed by pain (16 patients, 22.5\%). A complete list of stressors and their frequency is shown in Fig. 1.

When asked daily during their ICU stay if they had slept at night, 63 patients (88.7\%) mentioned disturbed sleep during their ICU stay, and eight patients (11.3\%) said they had slept without disturbance on all nights. The mean RCSQ score was $59.66 \pm 15.18$. The RCSQ scores according to stressors, age, and ICU stay length are shown in Table 1.

Analysis of the most frequent factors mentioned by patients (anxiety, pain, noise, and lights) showed that the most frequent factors associated with disturbed sleep at night were the biological factors anxiety symptoms $(p=$ 0.001 ; odds ratio $[\mathrm{OR}], 23.13$; $95 \%$ confidence interval [CI]: [2.87-186.10]) and pain $(p=0.001 ;$ OR, $1.61 ; 95 \%$ CI: $1.27-2.04)$. The associations between biological and environmental factors and a full night of sleep are shown in Table 2.
Table 1 RCSQ scores according to age, ICU stay length, and stressors

\begin{tabular}{lll}
\hline & RCSQ score & $\boldsymbol{p}$ value \\
\hline $\begin{array}{l}\text { Age groups } \\
\leq 55 \text { years }\end{array}$ & $57.17 \pm 13.69$ & \\
$>55$ years & $62.22 \pm 16.39$ & \\
Duration of ICU stay & & \\
$\quad \leq 5$ days & $59.99 \pm 17.41$ & 0.848 \\
$>5$ days & $59.29 \pm 12.40$ &
\end{tabular}

Stressors

\section{Biological factors}

Anxiety symptoms

$$
\text { Yes }
$$

$60.70 \pm 11.54$

No

$59.22 \pm 16.54$

Pain

Yes

$57.53 \pm 11.62$

No

$60.28 \pm 16.11$

Environmental factors

$$
\begin{gathered}
\text { Noise } \\
\text { Yes }
\end{gathered}
$$

$49.26 \pm 14.20$

0.001

No

$64.65 \pm 13.06$

Lighting

Yes

$49.06 \pm 16.54$

0.003

$R C S Q$ Richards-Campbell Sleep Questionnaire

The data are expressed as mean \pm standard deviation, $p$ values were obtained using Student's t test

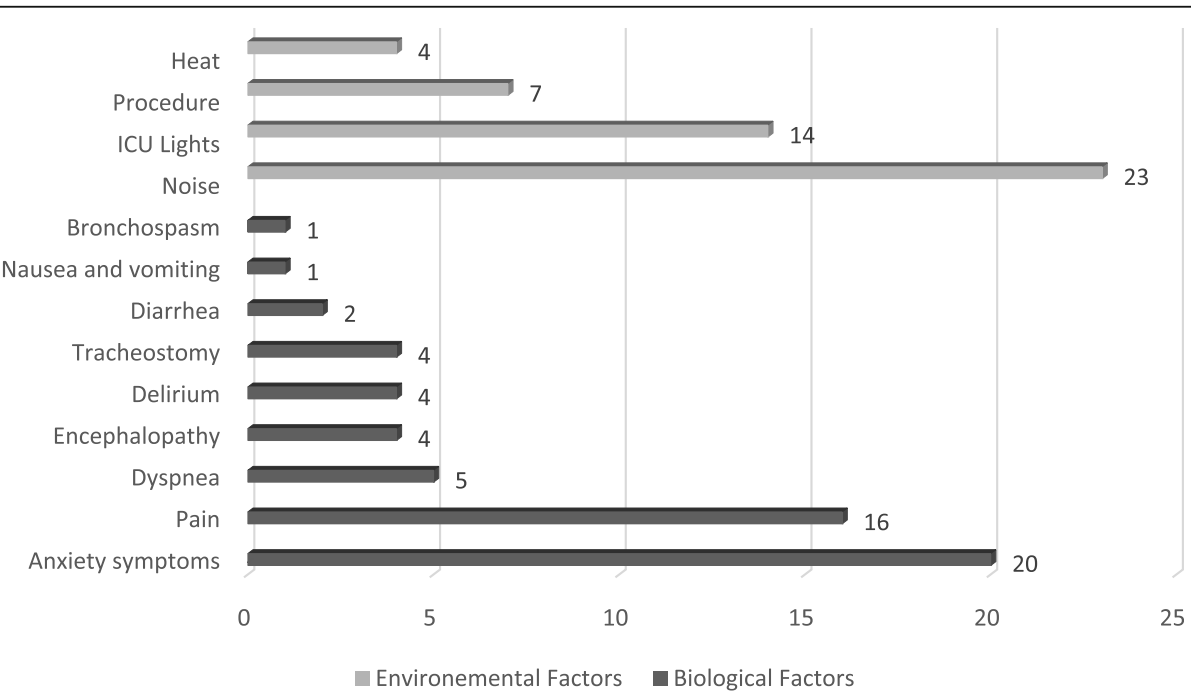

Fig. 1 Prevalence of biological and environmental stressors 
Table 2 Patients' report of a full night of sleep and stressors

\begin{tabular}{lllll}
\hline & \multicolumn{2}{l}{ Full night of sleep } & $p$ value & $\begin{array}{l}\text { Odds ratio } \\
(95 \% \mathrm{Cl})\end{array}$ \\
\cline { 2 - 3 } & Yes & No & & \\
\hline Biological factors & & & & \\
Anxiety symptoms & $1(1.4 \%)$ & $19(26.7 \%)$ & 0.001 & $23.13(2.87-186.10)$ \\
$\begin{array}{l}\text { Pain } \\
\text { Environmental factors }\end{array}$ & $16(22.5 \%)$ & 0.001 & $1.61(1.27-2.04)$ \\
$\quad$ & & & \\
Noise & $6(8.4 \%)$ & $17(23.9 \%)$ & 0.121 & $2.60(0.87-7.74)$ \\
ICU lights & $6(8.4 \%)$ & $8(11.2 \%)$ & 1.00 & $0.90(0.27-2.94)$ \\
\hline
\end{tabular}

Note: $p$ values were obtained using the chi-squared test

A higher percentage of patients in the younger group were affected by biological factors; 26 patients $(72.2 \%)$ in the $\leq 55$-year-old group and 16 patients $(45.7 \%)$ in the older age group were affected by biological factors $(p=$ 0.031, OR, 0.32; 95\% CI: 0.12-0.86). A higher percentage of patients in the younger group was also affected by environmental factors: 17 patients $(47.2 \%)$ in the $\leq 55$ year-old group and 13 patients (37.1\%) in the $>55$-yearold group $(p=0.474)$. The distributions of biological and environmental factors according to age groups and duration of hospital stay are shown in Table 3.

\section{Noise level}

The global noise level was $62.45 \pm 3.7 \mathrm{~dB}$. When analyzed according to shift, the noise levels were $62.5 \pm$ $3.72 \mathrm{~dB}$ during the morning shift, $62.88 \pm 3.41 \mathrm{~dB}$ during the afternoon shift, and $61.89 \pm 3.89 \mathrm{~dB}$ during the night shift.

Table 3 Frequency of factors according to age and duration of hospital stay

\begin{tabular}{|c|c|c|c|c|}
\hline \multicolumn{5}{|l|}{ Age } \\
\hline $\begin{array}{l}\text { Biological } \\
\text { factors }\end{array}$ & $\begin{array}{l}\leq 55 \text { years } \\
(n=36)\end{array}$ & $\begin{array}{l}>55 \text { years } \\
(n=35)\end{array}$ & $p$ value & $\begin{array}{l}\text { Odds ratio } \\
(95 \% \mathrm{Cl})\end{array}$ \\
\hline $\begin{array}{l}\text { Anxiety } \\
\text { symptoms }\end{array}$ & $14(38.8 \%)$ & $6(17.1 \%)$ & 0.064 & $0.32(0.10-0.98)$ \\
\hline Pain & $11(30.5 \%)$ & $5(14.2 \%)$ & 0.155 & $0.37(0.11-1.23)$ \\
\hline \multicolumn{5}{|c|}{ Environmental factors } \\
\hline Noise & $16(44.4 \%)$ & $7(20 \%)$ & 0.042 & $0.31(0.10-0.90)$ \\
\hline Lights & $11(30.5 \%)$ & $3(8.5 \%)$ & 0.035 & $0.21(0.05-0.84)$ \\
\hline \multicolumn{5}{|c|}{ ICU stay length } \\
\hline $\begin{array}{l}\text { Biological } \\
\text { factors }\end{array}$ & $\begin{array}{l}\leq 5 \text { days of } \\
(n=38)\end{array}$ & $\begin{array}{l}>5 \text { days } \\
(n=33)\end{array}$ & $p$ value & $\begin{array}{l}\text { Odds ratio } \\
(95 \% \mathrm{Cl})\end{array}$ \\
\hline $\begin{array}{l}\text { Anxiety } \\
\text { symptoms }\end{array}$ & $4(10.5 \%)$ & $16(48.4 \%)$ & 0.001 & $\begin{array}{l}8.00(2.31- \\
27.66)\end{array}$ \\
\hline Pain & $7(18.4 \%)$ & $9(27.2 \%)$ & 0.407 & $1.66(0.54-5.10)$ \\
\hline \multicolumn{5}{|c|}{ Environmental factors } \\
\hline Noise & $8(21 \%)$ & $15(45.4 \%)$ & 0.042 & $3.12(1.10-8.82)$ \\
\hline Lights & $5(13.1 \%)$ & $9(27.2 \%)$ & 0.231 & $2.47(0.73-8.32)$ \\
\hline
\end{tabular}

Notes: $p$ values were obtained using the chi-squared test
The global noise level was $62.66 \pm 1.23 \mathrm{~dB}$ in the general ICU. The noise levels were $63.17 \pm 1.33 \mathrm{~dB}$, $63.11 \pm 0.63 \mathrm{~dB}$, and $61.69 \pm 1.11 \mathrm{~dB}$ during the morning, afternoon, and night shifts, respectively. These differences were significant ( $p=0.018$, one-way ANOVA). The global noise level was $62.25 \mathrm{~dB} \pm 1.45$ in the stepdown unit. The noise levels were $62.01 \pm 1.71 \mathrm{~dB}$, $62.65 \pm 1.46 \mathrm{~dB}$, and $62.08 \pm 1.27 \mathrm{~dB}$ during the morning, afternoon, and night shifts, respectively $(p=0.654$, oneway ANOVA). A comparison between noise levels in the general ICU and the step-down unit is shown in Fig. 2. The global and shift mean sound levels are shown in Table 4.

We examined whether the physical characteristics of the ICUs were related to the perception of sound. Schematic drawings of the layout of the units are shown in Figs. 3 and 4. The highest noise level was observed in unit $13(65.15 \pm 1.93 \mathrm{~dB})$, followed by units $2(64.63 \pm$ $2.36 \mathrm{~dB})$ and $12(63.86 \pm 1.65 \mathrm{~dB})$. The lowest noise level was observed in units $5(59.56 \pm 7.47 \mathrm{~dB}), 3(60.41 \pm 5.22$ $\mathrm{dB})$, and $16(60.62 \pm 2.12 \mathrm{~dB})$.

We examined whether the sound levels were associated with sleep disturbance caused by other stressors. The global noise level was significantly related to sleep disturbance in patients who reported pain as a biological factor during the night $(p=0.037)$. Similarly, the sound level during the night shift was significantly related to sleep disturbance in patients who reported pain as a biological factor during the night $(p=0.025)$. The associations between stressors and sound level are shown in Table 5.

\section{Discussion}

We found that environmental and biological factors negatively affected sleep quality in patients admitted to the ICU in a private hospital. These findings contrast with those of other studies that reported noise as the most prominent stressing factor [5, 21-23]. Noise perceived by ICU patients is a major environmental factor that can interrupt patients' sleep. We measured the sound levels at different times throughout the day and night and found that sound level ranged from 40 to 80 $\mathrm{dB}$, as previously reported $[13,24-26]$. The sound levels measured in ICUs exceed those recommended by the WHO [16]. The US Centers for Disease Control and Prevention (CDC) states that the maximum level of sound a human ear can sustain is $140-150 \mathrm{~dB}$. Although patients are not exposed to extreme sound levels in the ICU, the CDC also states that $70-85 \mathrm{~dB}$ can be harmful after $2 \mathrm{~h}$ of exposure [27]. This is vital information given that a study of the sound levels in ICU rooms and general ward rooms reported that ICU rooms were not only louder than those in general wards, but that the sound 


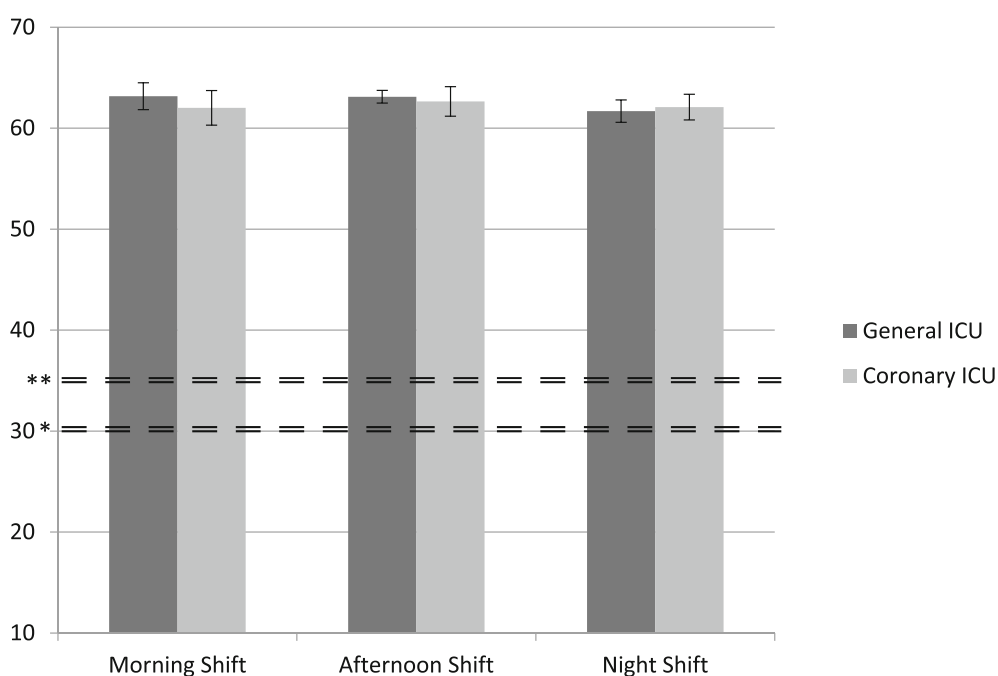

Fig. 2 Comparison between the general ICU and the step-down unit sound levels shown according to work shift. * dB recommended by the World Health Organization $(\mathrm{WHO})$ during the night. ${ }^{* *} \mathrm{~dB}$ recommended by the WHO during the day

level appeared as several peaks $>85 \mathrm{~dB}$ across $24-72 \mathrm{~h}$ of recording in the ICU [20].

We found that the units with the most noise were located next to the entrance to the ICU and the nursing station in the step-down unit. Noise in the nursing station related mainly to chair movement, alarms, staff conversations, and telephones. An example of this difference was observed in unit 16, which had the lowest levels recorded from all other step-down units, probably because of the distance between the unit and the nursing station. Coincidentally, one unit (unit 14) was "blocked" from this sound source by a structural beam and its noise level was lower. For example, the mean sound levels were $65.15 \mathrm{~dB}$ in unit 13 and $63.86 \mathrm{~dB}$ in unit 12, but $62.02 \mathrm{~dB}$ in unit 14 (Fig. 4). This contrasts with the noise levels in unit $11(63.43 \mathrm{~dB})$, which had no

Table 4 Comparison of sound levels between different ICU units and shifts

\begin{tabular}{|c|c|c|c|c|}
\hline Type of ICU & Global ICU stay & Morning shift & Afternoon shift & Night shift \\
\hline \multicolumn{5}{|l|}{ General ICU } \\
\hline 1 & $62.95 \pm 1.89$ & $64.08 \pm 2.99$ & $62.66 \pm 2.18$ & $62.12 \pm 1.10$ \\
\hline 2 & $64.63 \pm 2.36$ & $66.40 \pm 3.25$ & $64.00 \pm 1.56$ & $63.50 \pm 2.26$ \\
\hline 3 & $60.41 \pm 5.22$ & $60.92 \pm 5.24$ & $60.92 \pm 6.06$ & $59.40 \pm 4.40$ \\
\hline 4 & $63.63 \pm 1.03$ & $64.52 \pm 1.97$ & $64.20 \pm 1.04$ & $62.17 \pm 0.88$ \\
\hline 5 & $59.56 \pm 7.47$ & $62.22 \pm 1.79$ & $58.54 \pm 10.22$ & $57.92 \pm 10.91$ \\
\hline 6 & $61.66 \pm 3.30$ & $62.90 \pm 1.63$ & $61.70 \pm 3.61$ & $60.40 \pm 2.59$ \\
\hline 7 & $63.20 \pm 0.83$ & $63.24 \pm 1.49$ & $64.02 \pm 1.80$ & $62.34 \pm 1.15$ \\
\hline 8 & $60.80 \pm 0.52$ & $60.75 \pm 0.64$ & $61.40 \pm 2.55$ & $60.25 \pm 3.46$ \\
\hline \multicolumn{5}{|c|}{ Step-down unit } \\
\hline 9 & $61.56 \pm 1.88$ & $60.95 \pm 3.28$ & $61.60 \pm 1.83$ & $62.15 \pm 0.79$ \\
\hline 10 & $61.56 \pm 0.91$ & $60.60 \pm 1.21$ & $62.48 \pm 1.90$ & $61.62 \pm 1.02$ \\
\hline 11 & $63.43 \pm 2.40$ & $61.95 \pm 1.57$ & $62.48 \pm 1.27$ & $65.86 \pm 6.42$ \\
\hline 12 & $63.86 \pm 1.65$ & $63.52 \pm 2.55$ & $64.00 \pm 1.36$ & $64.06 \pm 2.19$ \\
\hline 13 & $65.15 \pm 1.93$ & $64.22 \pm 1.06$ & $65.48 \pm 2.79$ & $65.76 \pm 3.17$ \\
\hline 14 & $62.02 \pm 0.32$ & $62.11 \pm 0.56$ & $62.23 \pm 2.57$ & $61.71 \pm 2.06$ \\
\hline 15 & $61.16 \pm 1.11$ & $61.33 \pm 2.29$ & $61.65 \pm 1.59$ & $60.50 \pm 1.40$ \\
\hline 16 & $60.62 \pm 2.12$ & $60.25 \pm 2.94$ & $60.95 \pm 1.99$ & $60.68 \pm 3.32$ \\
\hline Total & $62.25 \pm 2.93$ & $62.33 \pm 2.62$ & $62.38 \pm 3.60$ & $62.03 \pm 4.23$ \\
\hline
\end{tabular}

The data are expressed as mean $\mathrm{dB} \pm$ standard deviation 


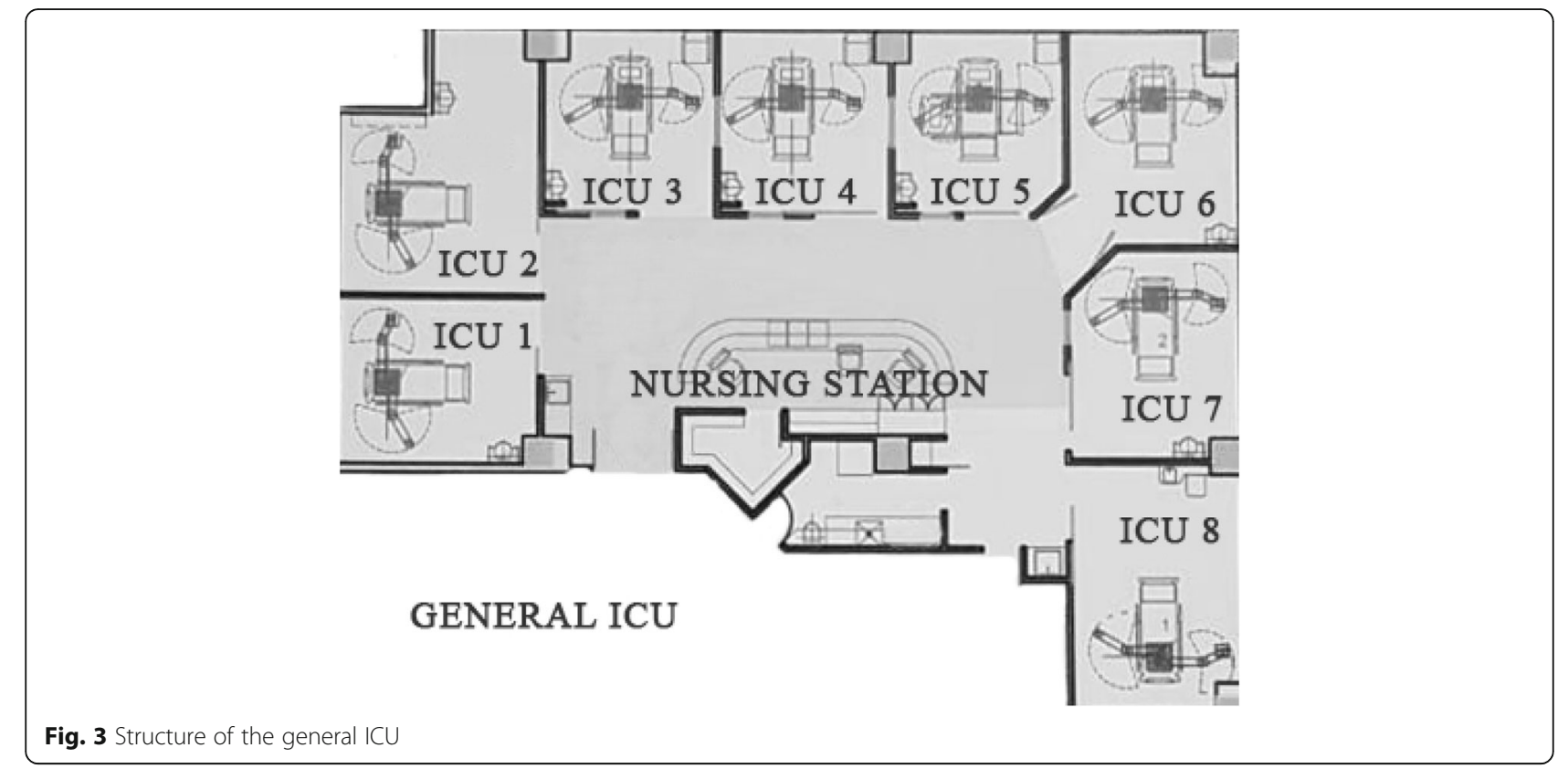

structural beam blocking the sound (Fig. 4). A previous study showed that it is possible to reduce noise perception with architectonic modifications [22]. Although the structural beam is part of the hospital's construction and was not constructed to interrupt the noise, this observation suggests that structures within the ICU may help to reduce noise; this may be important because ICU units do not usually have doors or, if they do, they are kept

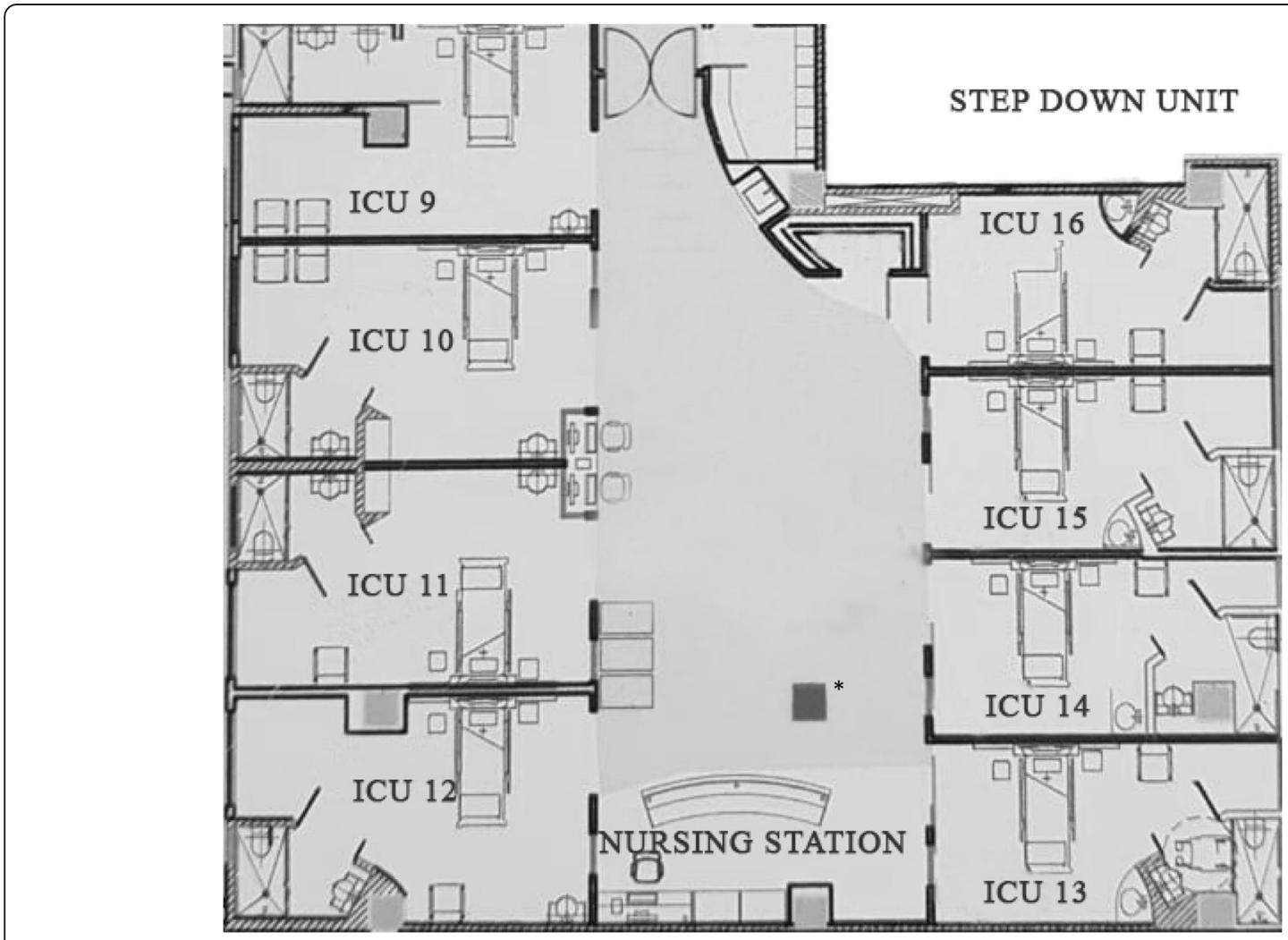

Fig. 4 Structure of the step-down unit. *Structural beam 
Table 5 Associations between stressors and sound level

\begin{tabular}{|c|c|c|c|c|c|c|c|c|}
\hline & Morning shift & $p$ value & Afternoon shift & $p$ value & Night shift & $p$ value & Global ICU stay & $p$ value \\
\hline \multicolumn{9}{|c|}{ Biological factors } \\
\hline \multicolumn{9}{|c|}{ Anxiety symptoms } \\
\hline Present & $61.81 \pm 2.53$ & 0.283 & $62.07 \pm 2.72$ & 0.597 & $61.75 \pm 4.56$ & 0.737 & $61.87 \pm 2.76$ & 0.488 \\
\hline Absent & $62.55 \pm 2.54$ & & $62.50 \pm 3.09$ & & $62.15 \pm 4.13$ & & $62.40 \pm 3.00$ & \\
\hline \multicolumn{9}{|l|}{ Pain } \\
\hline Present & $62.83 \pm 1.67$ & 0.269 & $62.98 \pm 2.30$ & 0.322 & $64.10 \pm 4.49$ & 0.025 & $63.30 \pm 1.98$ & 0.037 \\
\hline Absent & $62.19 \pm 2.83$ & & $62.20 \pm 3.89$ & & $61.43 \pm 3.99$ & & $61.94 \pm 3.09$ & \\
\hline \multicolumn{9}{|c|}{ Environmental factors } \\
\hline \multicolumn{9}{|l|}{ Noise } \\
\hline Present & $62.22 \pm 2.36$ & 0.784 & $62.79 \pm 2.00$ & 0.411 & $62.62 \pm 1.51$ & 0.274 & $62.54 \pm 1.49$ & 0.459 \\
\hline Absent & $62.40 \pm 2.75$ & & $62.18 \pm 4.15$ & & $61.75 \pm 5.03$ & & $62.11 \pm 3.41$ & \\
\hline \multicolumn{9}{|l|}{ Lights } \\
\hline Present & $62.04 \pm 2.82$ & 0.661 & $62.10 \pm 2.09$ & 0.646 & $62.40 \pm 1.46$ & 0.537 & $62.18 \pm 1.70$ & 0.886 \\
\hline Absent & $62.41 \pm 2.58$ & & $62.45 \pm 3.88$ & & $61.95 \pm 4.67$ & & $62.27 \pm 3.16$ & \\
\hline
\end{tabular}

The data are expressed as mean $\mathrm{dB} \pm$ standard deviation, $\mathrm{p}$ values were obtained using Student's $\mathrm{t}$ test

partially open door to facilitate entrance by physicians and nursing personnel in case of emergency. However, this arrangement allows the noise of the ICU to enter the rooms and disturb the patients' sleep, primarily during the night shift.

Second to noise, anxiety was the next most frequent biological stressor described by patients. Noise is considered to be one of the main aggravating factors related to the development of anxiety during a hospital stay [28]. We found that patients older than 55 years had a lower prevalence of anxiety during their hospital stay, suggesting that age may offer some level of protection against the development of anxiety symptoms. The presence of anxiety and stress symptoms seemed to be higher in younger patients but to be less disruptive with increasing length of hospital stay: a finding that has also been reported by Ayllón-Garrido et al. [29]. It is important to identify anxiety and stress promptly during and after hospitalization in the ICU because patients experiencing these are susceptible to developing cognitive psychological distress, anxiety, and depression, which increase the risk of poor recovery and decrease quality of life after ICU discharge [30, 31].

The second most common biological stressing factor was pain. Studies have shown that $20-75 \%$ of patients report that pain alters their sleep [9, 29, 32, 33]. Stress caused by noise has been shown to increase the pain threshold in both animal and human experimentation models [34, 35]. In our patients, the presence of pain was significantly associated with perceived noise levels within the ICU for both the night shift and global hospital stay. These findings suggest that noise in the ICU during daytime can also affect patients' sleep. It seems that the longer the hospital stay is, the stronger the effect of pain as a stressing factor that can affect patients' sleep becomes. Additionally, we found that none of the patients who reported pain as a factor during the night had a full night of sleep during their hospital stay. Sleep deprivation can, to some extent, increase the stress of being hospitalized and decrease the patient's pain threshold [36, 37].

Almost $20 \%$ of our patients associated their sleep disturbances with the ICU's lighting. This is a higher percentage than that reported in the literature [38]. ICUs require continuous lighting for management of patient care, but such lighting can suppress melatonin secretion, which can alter the circadian cycle [39]. Even low lighting, such as indoor lighting, can affect a patient's sleep schedule, although it is not a prominent factor that disrupts sleep [40-42]. Some critically ill patients are placed in a decubitus position for $>24 \mathrm{~h}$ at a time, which can alter their circadian cycle and lead to modifications of their sleep schedule, for example by causing them to sleep during the day but remain awake at night because of the lack of natural lighting, loss of the sense of day and night, and excessive nocturnal noise. Alterations in the circadian cycle can affect the sleep cycle and thermal regulation, which may increase a patient's susceptibility to complications such as sepsis and poor recovery in addition to their initial pathology [12, 41].

Physicians and hospital personnel should be aware that noise in the ICU can affect patients' sleep patterns and that both environmental and biological factors can directly affect patients' sleep. Studies 
have noted the importance of improving the environment to promote healthier sleep and overall quality of life during ICU admission [43-46]. One proposed solution is the introduction of "quiet times" for patients admitted to the ICU, when patients are given a period of reduced noise and light stimuli with the objective of improving sleep. Several studies have reported improvement in sleep quality at night and in the overall ICU environment in both patients and hospital personnel after the implementation of quiet times [9, 47-49]. These findings suggest that this intervention may help to prevent pain in patients rather than treating pain as it appears. Additionally, in patients already experiencing pain, pharmaceutic measures (such as NSAIDS, ketamine, or opioids) and nonpharmaceutical approaches (such as massage, hypnosis, ear plugs sleeping masks or music therapy) may be beneficial [2]. These options may also help relieve sleeping difficulties in different circumstances such as agitation, immobility, and sleep disturbances. Physicians can provide patients with medical and nonmedical means of controlling the stressing factors encountered in the ICU to maximize the therapeutic environment when treating an already complicated patient. Hopefully, this will lead to a faster and better recovery.

One limitation of this study is that sound was measured three times a day in the morning, afternoon, and night, because the research team could not perform $24 \mathrm{~h}$ continuous recording for the exact measurement of the sound levels in each unit. We compromised by measuring the sound level at different times each day to obtain a more realistic measurement of the global sound panorama in the ICU (e.g., visiting and nonvisiting hours, shift changes). Another limitation is the assessment of anxiety. We did not use a specific instrument to measure anxiety and relied on the patients' subjective perception of anxiety.

\section{Conclusions}

The most frequent factors associated with sleep disturbance in the ICU were anxiety symptoms, pain, ICU lighting, and noise made by hospital staff, vital sign monitors, and infusion pumps. The ability of a patient to recover in the ICU depends on good quality sleep, and this should be a priority for hospital personnel. We suggest the use of earplugs and sleeping masks for patients whose condition allows. We also encourage nursing and medical staff to decrease the noise made by their activities within the units, to be alert to medication that can disrupt patients' sleep, and to devise strategies to adjust alarms to the individual needs of each patient. Implementation of these measures and other structural modifications may help reduce the sound levels and help patients in the ICU attain good sleep quality.

\section{Abbreviations}

ANOVA: Analysis of variance; CDC: US Center for Disease Control and Prevention; Cl: Confidence interval; $\mathrm{dB}$ : Decibel; ICU: Intensive care unit; OR: Odds ratio; RCSQ: Richards-Campbell Sleep Questionnaire; WHO: World Health Organization

\section{Acknowledgements}

The authors of the manuscript thank the participants of the study for their cooperation, and OnLine English for editing the manuscript and reviewing it for language, structure, and expression of ideas suitable for publication in the biomedical literature. The authors thank Dr. Kathy C. Richards for granting permission for the use of the Richard-Campbell Sleep

Questionnaire.

\section{Authors' contributions}

RCMA, MLT, and ACGC conceived the study. RCMA, MLT, ACGC, CJZFV, ABH, and LAGG assisted with the patient recruitment process and measurement of the sound levels within the units. RCMA, MLT, ACGC, AOCF, KJPB, BGGR, and GMV coordinated the daily surveys and follow-up of the patients admitted to the ICU. CZJFV, ABH, LAGG, KJPB, BGGR, FJBC, CFO, and AGO assisted with the creation and management of the database. MLT, ACGC, RCMA, AOCF, GMV, CFO, and AGO contributed to the design and implementation of the research, analysis of the results. All authors contributed to the writing of the manuscript. All authors read and approved the final manuscript.

\section{Funding}

The authors declare that no funding was received for the present study.

\section{Availability of data and materials}

The datasets used and/or analyzed during the current study are available from the corresponding author on reasonable request.

\section{Ethics approval and consent to participate}

Participants were fully informed about the study, written consent was obtained from each research participant before the study. Their privacy, confidentiality, and anonymity were ensured. The study protocol was approved by the Ethics and Research Committee of the San Javier Hospital with the registration number SJ28012018154602. The authors state that all interventions comply with the ethical standards of the relevant national and institutional committees on human experimentation in accordance with the Declaration of Helsinki and the Mexican Health Guidelines.

Consent for publication

Not applicable.

Competing interests

The authors declare that they have no competing interests.

\section{Author details}

${ }^{1}$ Hospital San Javier, Guadalajara, Jalisco, Mexico. ${ }^{2}$ Unidad de Investigación Biomédica 02, Hospital de Especialidades del Centro Médico Nacional de Occidente, Instituto Mexicano del Seguro Social, Avenida Belisario Domínguez \# 1000 Col. Independencia, 44340 Guadalajara, Jalisco, Mexico.

Received: 19 March 2020 Accepted: 1 July 2020

Published online: 09 July 2020

\section{References}

1. De Jonghe B, Cook D, Griffith L, Appere-De-Vecchi C, Guyatt G, Théron V, et al. Adaptation to the intensive care environment (ATICE): development and validation of a new sedation assessment instrument. Crit Care Med. 2003;31(9):2344-54.

2. Devlin JW, Skrobik Y, Gélinas C, Needham DM, Slooter AJC, Pandharipande PP, et al. Clinical practice guidelines for the prevention and management of pain, agitation/sedation, delirium, immobility, and sleep disruption in adult patients in the ICU. Crit Care Med. 2018;46(9):e825-73.

3. Simini B. Patients' perceptions of intensive care. Lancet. 1999;354(9178):571-2. 
4. Rotondi AJ, Chelluri L, Sirio C, Mendelsohn A, Schulz R, Belle S, et al. Patients' recollections of stressful experiences while receiving prolonged mechanical ventilation in an intensive care unit. Crit Care Med. 2002;30:746-52.

5. Johansson L, Bergbom I, Waye KP, Ryherd E, Lindahl B. The sound environment in an ICU patient room - a content analysis of sound levels and patient experiences. Intensive Crit Care Nurs. 2012;28(5):269-79.

6. Park M, Kohlrausch A, de Bruijn W, de Jager P, Simons K. Analysis of the soundscape in an intensive care unit based on the annotation of an audio recording. J Acoust Soc Am. 2014;135(4):1875-86.

7. Moser DK, Chung ML, McKinley S, Riegel B, An K, Cherrington CC, et al. Critical care nursing practice regarding patient anxiety assessment and management. Intensive Crit care Nurs. 2003;19(5):276-88.

8. Ryherd EE, Waye KP, Ljungkvist L. Characterizing noise and perceived work environment in a neurological intensive care unit. J Acoust Soc Am. 2008; 123(2):747-56

9. Carrera-Hernández L, Aizpitarte-Pejenaute E, Zugazagoitia-Ciarrusta N, GoñiViguria R. Patients' perceptions of sleep in a critical care unit. Enferm Intensiva. 2018;29(2):53-63.

10. Murphy M, Bruno M-A, Riedner BA, Boveroux P, Noirhomme Q, Landsness EC, et al. Propofol anesthesia and sleep: a high-density EEG study. Sleep. 2011;34(3):283-91A.

11. Delaney LJ, Van Haren F, Lopez V. Sleeping on a problem: the impact of sleep disturbance on intensive care patients - a clinical review. Ann Intensive Care. 2015;5(1):3.

12. Matthews EE. Sleep disturbances and fatigue in critically ill patients. AACN Adv Crit Care. 2011;22(3):204-24.

13. Aragón Albillos P, Capella Trigo L, Fernández González E, González Cuadrillero B, de Juana Morrondo S. Influencia de los factores ambientales en las alteraciones del sueño de los pacientes de una unidad coronaria [Influence of the environmental factors on dream's alterations at the coronary patients unit]. Enfermería en Cardiol. 2011; 53:40-4.

14. Garrido-Galindo AP, Camargo-Caicedo Y, Vélez-Pereira AM. Noise level in the intensive care unit for adults: measurement, international standards and health implications. Rev Univ Salud. 2015;17(2):163-9.

15. Bernal Ruiz DC, González Consuegra RV, Rojas Ruiz IT. Stressors in patients admitted to adult intensive care units. Referência. 2018;16:63-72.

16. Berglund B, Lindvall T, Schwela DH. Guidelines for community noise: World Health Organization; 1999. http://www.who.int/docstore/peh/noise/ guidelines2.html. Accessed 13 Mar 2020.

17. Nicolás A, Aizpitarte E, Iruarrizaga A, Vázquez M, Margall MA, Asiain MC. Perception of night-time sleep by the surgical patients in an intensive care unit. Enfermería Intensiva. 2002;13(2):57-67.

18. NANDA International. Diagnósticos enfermeros. In: Herdman H, Kamitsuru S, editors. Definiciones y clasificación 2015-2017. 1st ed. Elsevier; 2016.

19. House A, Stark D. Anxiety in medical patients. BMJ. 2002;325(7357):207.

20. Jaiswal SJ, Garcia S, Owens RL. Sound and light levels are similarly disruptive in ICU and non-ICU wards. J Hosp Med. 2017:12(10):798-804.

21. Gómez Sanz CA. Quality of sleep of patients admitted to the ICU: relationship with environmental stressors. Enfermería Intensiva. 2013;24(1):3-11.

22. Luetz A, Weiss B, Penzel T, Fietze I, Glos M, Wernecke KD, et al. Feasibility of noise reduction by a modification in ICU environment. Physiol Meas. 2016; 37(7):1041-55.

23. Xie H, Kang J, Mills GH. Clinical review: the impact of noise on patients' sleep and the effectiveness of noise reduction strategies in intensive care units. Crit Care. 2009;13(2):208.

24. Darbyshire $J$. Excessive noise in intensive care units. BMJ. 2016;353:11956.

25. Guillén Pérez F, Bernal Barquero M, García Díaz S, Josefa García Díaz M, Rosario Illán Noguera C, del Camino Álvarez Martínez M, et al. Calidad del sueño de los pacientes ingresados en $\mathrm{UCl}$ : relación con estresores ambientales. Enfermería Docente. 2013;100:34-9.

26. Ornelas-Aguirre JM, Zárate-Coronado O, Gaxiola-González F, Neyoy-Sombra $\checkmark$. Environmental noise levels in 2 intensive care units in a tertiary care Centre. Arch Cardiol México. 2018;88(4):253-60.

27. Centers for Disease Control and Prevention. What noises cause hearing loss? https://www.cdc.gov/nceh/hearing_loss/what_noises_cause_hearing_ loss.html. Accessed 10 June 2020

28. Ding Q, Redeker NS, Pisani MA, Yaggi HK, Knauert MP. Factors influencing patients' sleep in the intensive care unit: perceptions of patients and clinical staff. Am J Crit Care. 2017;26(4):278-86.
29. Ayllón Garrido N, Álvarez González M, González GM. Stressful environmental events in the intensive care unit. Enferm intensiva. 2007:18(4):159-67.

30. Hashmi AM, Han JY, Demla V. Intensive care and its discontents: psychiatric illness in the critically ill. Psychiatr Clin North Am. 2019;40(3):487-500.

31. Choi J, Tate JA, Rogers MA, Donahoe MP, Hoffman LA. Depressive symptoms and anxiety in intensive care unit (ICU ) survivors after ICU discharge. Heart Lung. 2019;45(2):140-6.

32. Chanques G, Sebbane M, Barbotte E, Viel E, Eledjam J-J, Jaber S. A prospective study of pain at rest: incidence and characteristics of an unrecognized symptom in surgical and trauma versus medical intensive care unit patients. Anesthesiology. 2007:107(5):858-60.

33. Nelson JE, Meier DE, Oei EJ, Nierman DM, Senzel RS, Manfredi PL, et al. Selfreported symptom experience of critically ill cancer patients receiving intensive care. Crit Care Med. 2001;29(2):277-82.

34. Kjellberg A. Subjective, behavioral and psychophysiological effects of noise. Scand J Work Environ Health. 1990;16(Suppl 1):29-38.

35. Shankar N, Awasthy N, Mago H, Tandon OP. Analgesic effect of environmental noise: a possible stress response in rats. Indian J Physiol Pharmacol. 1999;43(3):337-46.

36. Brand S, Gerber M, Pühse U, Holsboer-Trachsler E. The relation between sleep and pain among a non-clinical sample of young adults. Eur Arch Psychiatry Clin Neurosci. 2010;260(7):543-51.

37. Onen SH, Alloui A, Gross A, Eschallier A, Dubray C. The effects of total sleep deprivation, selective sleep interruption and sleep recovery on pain tolerance thresholds in healthy subjects. J Sleep Res. 2001;10(1):35-42.

38. Freedman NS, Kotzer N, Schwab RJ. Patient perception of sleep quality and etiology of sleep disruption in the intensive care unit. Am J Respir Crit Care Med. 1999;159(4):1155-62.

39. Zisapel N. New perspectives on the role of melatonin in human sleep, circadian rhythms and their regulation. Br J Pharmacol. 2018 Aug;175(16):3190-9.

40. Kamdar BB, Needham DM, Collop NA. Sleep deprivation in critical illness: its role in physical and psychological recovery. J Intensive Care Med. 2012; 27(2):97-111.

41. Drouot X, Quentin S. Sleep neurobiology and critical care illness. Crit Care Clin. 2015 Jul:31(3):379-91.

42. Meyer TJ, Eveloff SE, Bauer MS, Schwartz WA, Hill NS, Millman RP. Adverse environmental conditions in the respiratory and medical ICU settings. Chest. 1994;105(4):1211-6.

43. Park MJ, Yoo JH, Cho BW, Kim KT, Jeong W-C, Ha M. Noise in hospital rooms and sleep disturbance in hospitalized medical patients. Environ Health Toxicol. 2014 Aug 18;29:e2014006.

44. Patel J, Baldwin J, Bunting P, Laha S. The effect of a multicomponent multidisciplinary bundle of interventions on sleep and delirium in medical and surgical intensive care patients. Anaesthesia. 2014;69(6):540-9.

45. Kamdar BB, Yang J, King LM, Neufeld KJ, Bienvenu OJ, Rowden AM, et al. Developing, implementing, and evaluating a multifaceted quality improvement intervention to promote sleep in an ICU. Am J Med Qual. 2014 Nov 8:29(6):546-54.

46. Kamdar BB, King LM, Collop NA, Sakamuri S, Colantuoni E, Neufeld KJ, et al. The effect of a quality improvement intervention on perceived sleep quality and cognition in a medical ICU. Crit Care Med. 2013;41(3):800-9.

47. Maidl CA, Leske JS, Garcia AE. The influence of "quiet time" for patients in critical care. Clin Nurs Res. 2014;23(5):544-59.

48. Gardner G, Collins C, Osborne S, Henderson A, Eastwood M. Creating a therapeutic environment: a non-randomised controlled trial of a quiet time intervention for patients in acute care. Int J Nurs Stud. 2009;46(6):778-86.

49. Dennis CM, Lee R, Woodard EK, Szalaj JJ, Walker CA. Benefits of quiet time for neuro-intensive care patients. J Neurosci Nurs. 2010;42(4):217-24.

\section{Publisher's Note}

Springer Nature remains neutral with regard to jurisdictional claims in published maps and institutional affiliations. 